\title{
Relationship Between Cardiac Glycoside Contents and Color of Corchorus olitorius Seeds
}

\author{
Hiroshi Matsufuji, ${ }^{*}, a$ Shinobu Sakai, ${ }^{a}$ Makoto Chino, ${ }^{a}$ Yukihiro Goda, ${ }^{b}$ Masatake Toyoda, ${ }^{b}$ and \\ Mitsuharu Takeda ${ }^{a}$ \\ ${ }^{a}$ College of Bioresource Sciences, Nihon University, 1866 Kameino, Fujisawa, Kanagawa 252-8510, Japan and ${ }^{b}$ National Institute of \\ Health Sciences (NIHS), 1-18-1 Kamiyouga, Setagaya-ku, Tokyo 158-8501, Japan
}

(Received June 16, 2000; Accepted November 9, 2000)

\begin{abstract}
The relationship between the cardiac glycoside contents in Corchorus olitorius seeds and the seed color was examined. The seed color was assigned a shade (color value) ( $L$ value in UCS system). The dark grayish green seeds, showing lower $L$ value, contained more cardiac glycosides than dark grayish yellow seeds showing higher $L$ value. When the total cardiac glycoside contents were plotted against the $L$ values, a positive correlation $(\mathrm{r}=-0.913)$ was observed. Also, there was a higher content ratio of strophanthidin glycosides (erysimoside and olitoriside) in the seeds showing lower $L$ value, while there was a lower content ratio of digitoxigenin glycosides (coroloside and glucoevatromonoside) in the seeds showing lower $L$ value.
\end{abstract}

Key words — cardiac glycoside, Corchorus olitorius, seed color, strophanthidin, digitoxigenin

\section{INTRODUCTION}

Corchorus olitorius L. (Moroheiya) is extensively consumed as a "health vegetable" in Japan, because it contains abundant carotenoids, vitamin $\mathrm{B}_{1}, \mathrm{~B}_{2}, \mathrm{C}$ and $\mathrm{E}$, and minerals. On the other hand, the accidental death of cattle has occurred when the cattle were fed vegetation containing seeds, and it was concluded that the deaths were caused by cardiac glycosides in the seeds. Cardiac glycosides which were isolated from plant sources ${ }^{1,2)}$ are important pharmaceuticals widely used for the treatment of heart failure. Erysimoside, olitoriside, corchoroside $\mathrm{A}$, and helveticoside were found ${ }^{3-7)}$ from Corchorus species. The main cardiac glycosides are strophanthidin glycosides.

In a series of studies regarding safety of $C$. olitorius and its products, it was found that the wellmatured seeds contained not only strophanthidin glycosides but also digitoxigenin glycosides as coroloside, glucoevatromonoside, deglucocoroloside, evatromonoside, and digitoxigenin triglycoside (shown in Fig. 1), and that these cardiac glycosides did not exist in the edible green leaves and stem at all. ${ }^{8,9)}$ During the course of the

*To whom correspondence should be addressed: College of Bioresource Sciences, Nihon University, 1866 Kameino, Fujisawa, Kanagawa 252-8510, Japan. Tel.: +81-466-84-3988; Fax: +81-466-84-3986; E-mail: hmatsufu@brs.nihon-u.ac.jp studies, we found that the seed samples collected from some regions in our country are not uniform in color (dark grayish green $\sim$ dark grayish yellow), and that the sample consisting of mainly dark grayish green seeds contained more cardiac glycosides than those of mainly dark grayish yellow and dark grayish yellow-green seeds. ${ }^{10)}$ Thus, these results imply that dark grayish green seeds were more mature than the other colored seeds. To confirm the hypothesis, we studied relationships between the seed color and germination ratio, and the cardiac glycoside content ratio.

\section{MATERIALS AND METHODS}

Chemicals — The well-matured seeds of $C$. olitorius used in this experiment were obtained from four local public health centers in our country [Hamada (Shimane), Ohtake (Hiroshima), Kumagaya (Saitama), and Okayama (Okayama)], and Takii \& Co. Ltd. (Kyoto, Japan). These seeds were abbreviated as H1 (Hamada), H2 (Hamada), OT (Ohtake), K (Kumagaya), OK (Okayama), and EG (Takii \& Co., Ltd.; this seed is imported from Egypt). The distinctly dark grayish green, dark grayish yellow-green, or dark grayish yellow colored seeds were segregated from each other. This was done visually by a panel of observers. H1 was segregated into two groups (H1-1 and H1-2), $\mathrm{H} 2$ into 

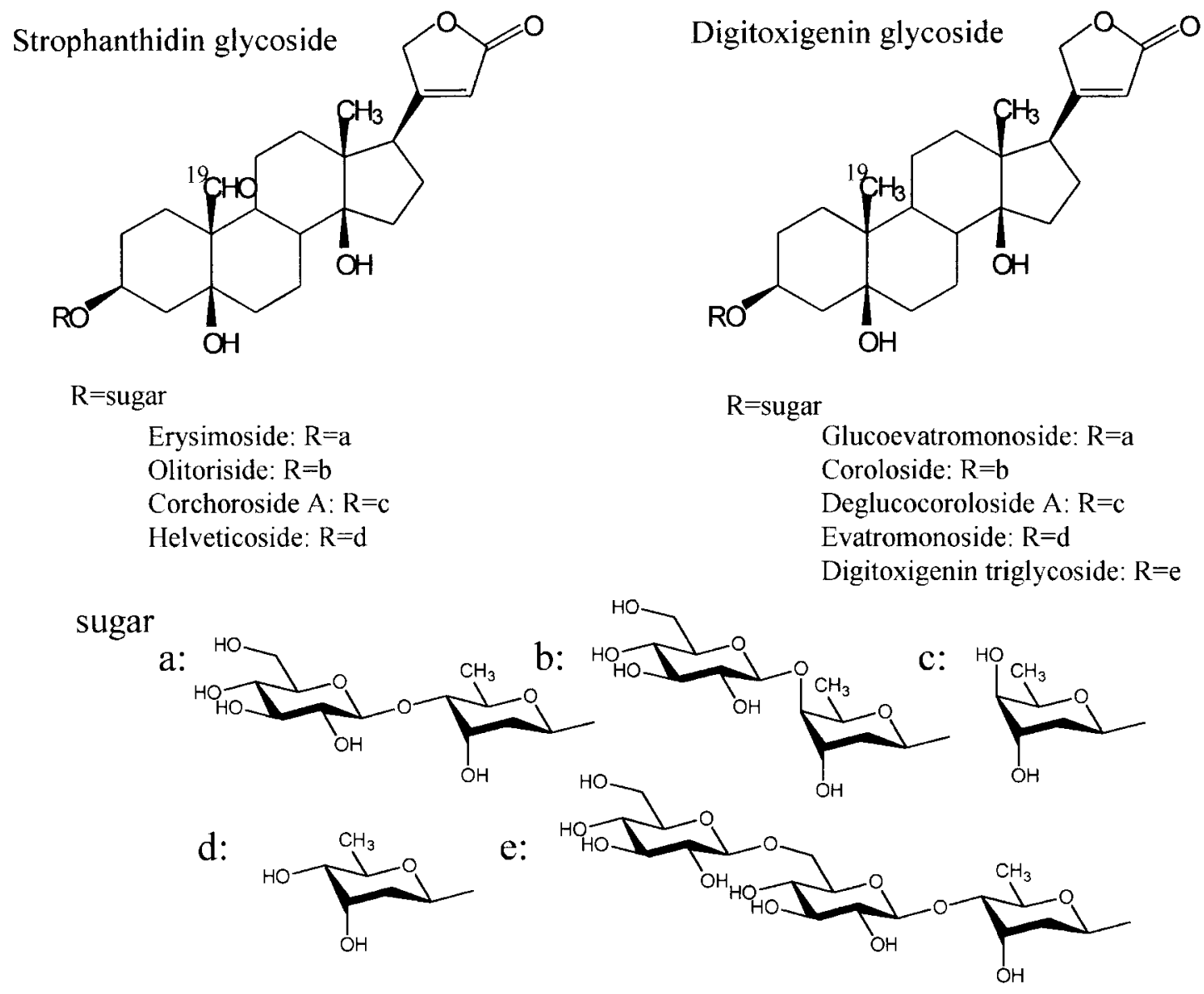

Fig. 1. Structures of Cardiac Glycosides from Seeds of C. olitorius

three groups (H2-1, H2-2, and H2-3), OT into two groups (OT-1 and OT-2), $\mathrm{K}$ into two groups (K-1 and $\mathrm{K}-2)$, and $\mathrm{OK}$ into three groups (OK-1, OK-2, and $\mathrm{OK}-3$ ).

Measurement of Seed Color — Surface color of the seeds was measured by using a MINOLTA CM503I spectrophotometer (Tokyo, Japan). The values of $L(0=$ black, $100=$ white $), a_{L}$ (+values $=$ red, -values $=$ green $)$, and $b_{L}(+$ values $=$ yellow, - values $=$ blue) were recorded. Table 1 shows the color data of the segregated seeds of $C$. olitorius.

Germination Test of the Seeds — A germination test was carried out in accordance with International Rules for Seed Testing. Fifty seeds were sown on water saturated filter paper (Toyo filter No. 2) in Petri dishes, and incubated in a growth chamber (Hitachi CR-20T) at $30^{\circ} \mathrm{C}$ under a photoperiod of $12 \mathrm{hr}$ light/ $12 \mathrm{hr}$ dark. The seeds were scored for germination after 5 day. These experiments were replicated six times.

Cardiac Glycoside Contents in C. olitorius Seeds The cardiac glycoside content in the seeds was calculated as the sum of erysimoside, olitoriside, corchoroside A, helveticoside, coroloside, and glucoevatromonoside, which were the main cardiac glycosides in C. olitorius seeds. ${ }^{10)}$ Glycoside contents were measured by high performance liquid chromatography (HPLC) according to a previous report. ${ }^{10)}$ The ground seeds $(300 \mathrm{mg})$ were delipidated with petroleum ether, and extracted with $5 \mathrm{ml}$ (two times) of methanol. The methanol fractions were combined and evaporated till dry. The residue was dissolved in $1.5 \mathrm{ml}$ of methanol, and the solution was directly chromatographed on an Inertsil ODS-3 column (4.6 mm i.d. $\times 250 \mathrm{~mm}$, GL Science Inc. Ltd., Tokyo, Japan) at $40^{\circ} \mathrm{C}$ with detection of $220 \mathrm{~nm}$. A mobile phase of $50 \%$ methanol was used at $1.0 \mathrm{ml} /$ min $(40 \%$ methanol was used for erysimoside and olitoriside).

\section{RESULTS AND DISCUSSION}

In order to investigate a relationship between the seed color and the degree of maturity, a germination test of the segregated seeds was done. As a result, 
Table 1. Color Data of $C$. olitorius in UCS System

\begin{tabular}{|c|c|c|c|c|c|c|c|}
\hline & Color of seeds* & & Shade $(L)$ & $a_{L}$ & $b_{L}$ & Chroma & Hue \\
\hline \multirow[t]{2}{*}{ H1 } & Dark grayish green $\sim$ & H1-1 & 45.31 & -7.43 & 4.48 & -0.60 & 8.68 \\
\hline & Dark grayish yellow & H1-2 & 55.16 & -5.51 & 8.75 & -1.59 & 10.34 \\
\hline \multirow[t]{3}{*}{$\mathrm{H} 2$} & Dark yellow $\sim$ & $\mathrm{H} 2-1$ & 51.87 & -5.99 & 2.43 & -0.41 & 6.46 \\
\hline & Dark grayish yellow & $\mathrm{H} 2-2$ & 55.33 & -10.42 & 7.15 & -0.69 & 12.64 \\
\hline & & $\mathrm{H} 2-3$ & 59.20 & -4.91 & 14.86 & -3.03 & 15.65 \\
\hline \multirow[t]{2}{*}{ OT } & Dark grayish yellow green $\sim$ & OT-1 & 49.34 & -8.48 & 5.20 & -0.61 & 9.95 \\
\hline & Dark grayish green & OT-2 & 56.31 & -3.84 & 10.98 & -2.86 & 11.63 \\
\hline \multirow[t]{3}{*}{$\mathrm{K}$} & Dark grayish green $\sim$ & $\mathrm{K}-1$ & 46.38 & -8.28 & 4.55 & -0.55 & 9.45 \\
\hline & Dark grayish yellow & K-2 & 50.44 & -5.31 & 7.82 & -1.47 & 9.45 \\
\hline & & OK-1 & 48.26 & -9.06 & 5.46 & -0.60 & 10.58 \\
\hline \multirow[t]{2}{*}{ OK } & Dark grayish green & OK-2 & 50.23 & -7.57 & 5.72 & -0.76 & 9.49 \\
\hline & & OK-3 & 53.49 & -2.35 & 10.91 & -4.64 & 11.16 \\
\hline EG & Dark green & EG & 45.70 & -7.55 & 3.45 & -0.46 & 8.30 \\
\hline
\end{tabular}

the dark grayish yellow seeds as H2-3, OT-2, and OK-3 scarcely germinated in this experiment, while the dark grayish green and green-yellow seeds were almost all germinated. Among the seed color parameters, the shade ( $L$ value) of the segregated seeds gave useful information; a sufficient straight line ( $\mathrm{r}$ $=-0.846$ ) between germination ratio and the $L$ values was obtained (Fig. 2). Thus, it was thought that the $L$ value of the seeds would be an indication of the degree maturity of $C$. olitorius seeds.

We also have tried to investigate a relationship between $L$ values and the total cardiac glycoside contents of the segregated seeds. Table 2 shows the cardiac glycoside contents of segregated seeds. The H1-1 seed showing the lowest $L$ value in this experiment contained the most cardiac glycoside content, while the H2-3 seed, the highest $L$ value, contained the least. As shown in Fig. 3, a good correlation $(\mathrm{r}=-0.913)$ was observed between the $L$ values and cardiac glycoside contents of segregated seeds. Therefore, this suggests that the more mature seeds contain more cardiac glycosides.

Since the methyl group is located at the 19-position in digitoxigenin and the aldehyde group is located at the 19-position in strophanthidin, digitoxigenin is thought to be an earlier compound in biosynthesis pathways than strophanthidin. Compared with aglycones in the segregated seeds, the proportion of strophanthidin diglycosides (erysimoside and olitoriside)/digitoxigenin diglycosides (coroloside and glucoevatromonoside) in the seeds showing lower $L$ value was smaller than that of the seeds

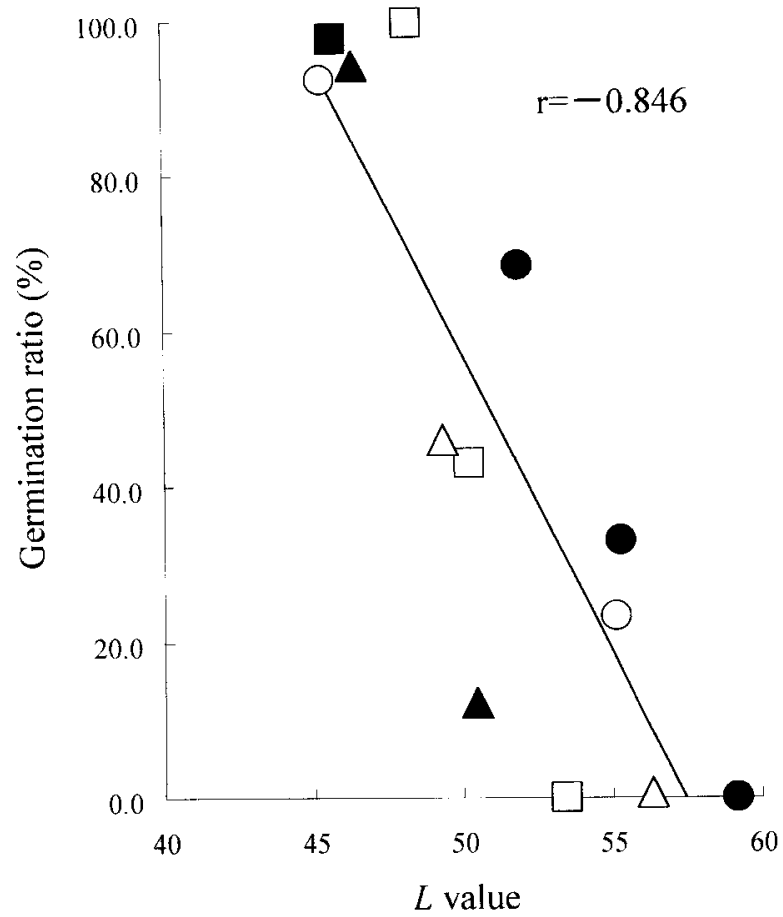

Fig. 2. Relationship between Germination Ratio and $L$ Value Symbols: $\mathrm{O}, \mathrm{H} 1 ; \triangle$, OT; $\square, \mathrm{OK} ; \bigcirc, \mathrm{H} 2 ; \boldsymbol{\Delta}, \mathrm{K} ; \mathbf{\square}, \mathrm{EG}$.

showing higher $L$ value. The plots gave a linear relationship with a correlation coefficient of -0.847 (data not shown). Thus, these findings suggest that the more mature seeds contained more cardiac glycosides, which were later compounds in biosynthesis such as strophanthidin.

In conclusion, the more mature seeds, that is, 
Table 2. Cardiac Glycoside Contents in the Segregated Seeds of $C$. olitrius

\begin{tabular}{lccccccc}
\hline \hline & $\begin{array}{c}\text { Cardiac glycoside } \\
(\mathrm{mg} / \mathrm{g})\end{array}$ & Erysimoside & Olitoriside & Corchoroside A & Helveticoside & Coroloside & Glucoevatromonoside \\
\cline { 2 - 7 } & 14.16 & 70.76 & 26.04 & 0.00 & 0.05 & 1.60 & 1.55 \\
H1-1 & 5.06 & 68.92 & 18.84 & 1.61 & 1.50 & 3.57 & 5.55 \\
H1-2 & 9.48 & 68.04 & 26.04 & 0.45 & 0.06 & 2.75 & 2.67 \\
H2-1 & 4.78 & 55.37 & 28.73 & 3.56 & 1.93 & 6.36 & 4.06 \\
H2-2 & 1.17 & 32.69 & 12.57 & 25.01 & 13.38 & 11.95 & 4.39 \\
H2-3 & 7.11 & 62.32 & 27.76 & 2.46 & 2.14 & 2.63 & 2.69 \\
OT-1 & 1.97 & 48.79 & 18.49 & 13.07 & 8.32 & 6.50 & 4.82 \\
OT-2 & 11.15 & 64.40 & 32.00 & 0.64 & 0.15 & 1.47 & 1.33 \\
K-1 & 5.33 & 59.77 & 24.75 & 1.60 & 1.11 & 5.58 & 7.20 \\
K-2 & 13.18 & 69.27 & 26.94 & 0.64 & 0.34 & 1.58 & 1.22 \\
OK-1 & 8.17 & 65.84 & 21.36 & 2.20 & 1.90 & 3.67 & 5.01 \\
OK-2 & 3.44 & 59.04 & 17.80 & 4.65 & 4.54 & 5.70 & 8.28 \\
OK-3 & 13.19 & 51.37 & 46.07 & 0.45 & 0.08 & 1.61 & 0.42 \\
EG & & & & & & & \\
\hline
\end{tabular}

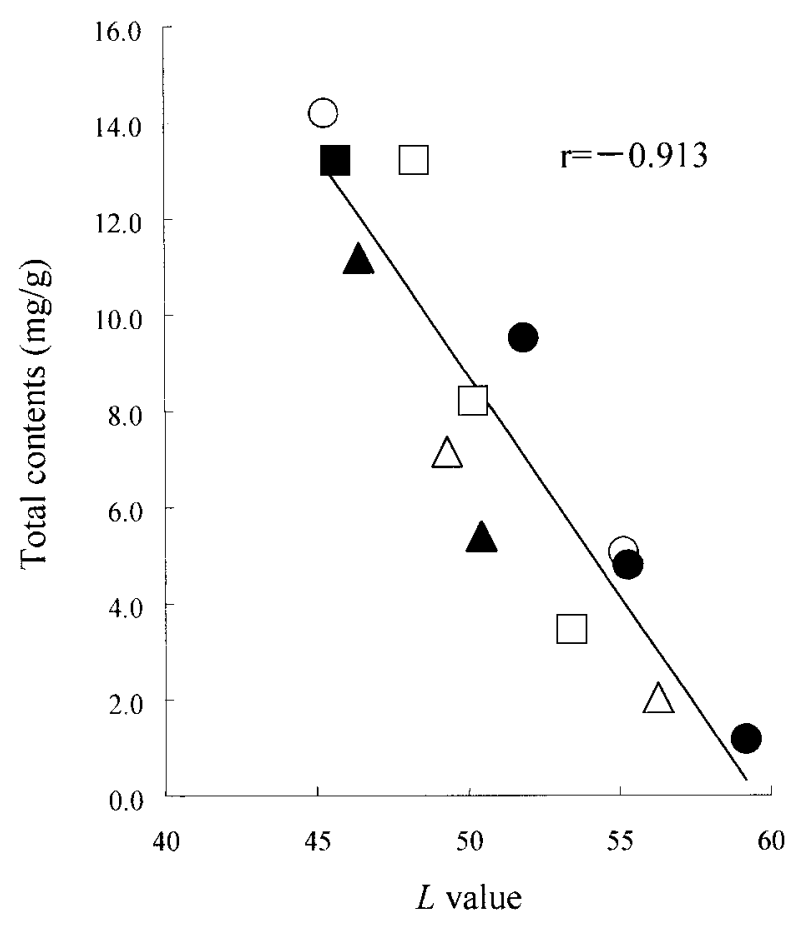

Fig. 3. Relationship between Total Cardiac Glycosides Contents and $L$ Value

Symbols: O, H1; $\triangle, \mathrm{OT} ; \square, \mathrm{OK} ; \bullet, \mathrm{H} 2 ; \mathbf{\Lambda}, \mathrm{K} ; \boldsymbol{\square}, \mathrm{EG}$.

the more dark colored seeds, contained more cardiac glycosides and more strophanthidin glycosides. On the other hand, the less mature seeds contained more digitoxigenin glycosides, although total cardiac glycoside content was less. Thus, the previous finding ${ }^{9,10)}$ that digitoxigenin glycosides were present in the seeds cultivated in Japan suggests that these glycosides would be identified by the different degree of maturity of the seeds. Also, seeds showing lower $L$ value, and containing more cardiac glycosides had a higher germination ratio. Yoshikawa $e t$ $a l .{ }^{11)}$ have reported that the cardiac glycosides disappeared within two weeks after germination, although they were present in the seeds. The cardiac glycosides in seeds may play some role in deterring germination and/or growth, although further studies are needed to clarify the reason.

\section{REFERENCES}

1) Theurer, C., Kreis, W. and Reinhard, E. (1998) Effects of digitoxigenin, digoxigenin, and various cardiac glycosides on cardenolide accumulation in shoot culture of Digitalis lanata. Planta Medica, 64, 705-710.

2) Mráz, M., Opletal, L., Sovová, M., Drašar, P. and Havel, M. (1992) Inhibition of $\mathrm{Na}^{+}, \mathrm{K}^{+}$-ATPase by the glycosides from Coronilla varia. Planta Medica, 58, 467-468.

3) Mahato, S. B., Sahu, N. P., Roy, S. K. and Pramanik, B. K. (1989) Cardiac glycosides from Corchorus olitorius. J. Chem. Soc. Perkin Trans. I, 2065-2068.

4) Maslennikova, V. A. and Abubakirov N. K. (1975) Jute glycosides. V. Coroloside and deglucocoroloside. Khim. Prir. Soedin., 11, 525-526.

5) Turakhozhaev, M. T., Zubkova, L. P., Shamsutdinov, M. I., Genkina, G. L. and Shakirov, T. T. (1972) Preparation of olitoriside from Corchorus olitorius seeds. Khim. Prir. Soedin., 8, 81-83.

6) Rao, E. V., Rao, K. N. and Rao, D. V. (1973) Cardenolides from the seeds of Corchorus olitorius. Curr. Sci., 42, 731-732.

7) Schenk, B., Junior, P. and Wichtl, M. (1980) 
Cannogenol-3-O- $\alpha$-L- rhamnoside and cannogenol3-O- $\beta$-D-allomethyloside, two new cardiac glycosides from Convallaria majalis. Planta Medica, 40, 1-11.

8) Nakamura, T., Goda, Y., Sakai, S., Kondo, K., Akiyama, H. and Toyoda, M. (1998) Cardenolide glycosides from seeds of Corchorus olitorius. Phytochemistry, 49, 2097-2101.

9) Goda, Y., Sakai, S., Nakamura, T., Kondo, K., Akiyama, H. and Toyoda, M. (1998) Determination of digitoxigenin glycosides in "Moroheiya" (Corchorus olitorius) and its products by HPLC. $J$. Food Hyg. Soc. Japan (SHOKUHIN EISEIGAKU
ZASSHI), 39, 415-420.

10) Goda, Y., Sakai, S., Nakamura, T., Akiyama, H. and Toyoda, M. (1998) Identification and analyses of main cardiac glycosides in Corchorus olitorius seeds and their acute oral toxicity to mice. J. Food Hyg. Soc. Japan (SHOKUHIN EISEIGAKU ZASSHI), 39, 256-265.

11) Yoshikawa, M., Murakami, T., Shimada, H., Fukuda, N., Matsuda, H., Sashida, Y. and Yamahara, J. (1998) Corchorusosides A, B, C, D, and E, new cardiotonic oligoglycosides from the seeds of Corchorus olitorius L. (Moroheiya). Heterocycles, 48, 869-873. 